\title{
Endocannabinoid Modulation of Predator Stress-Induced Long-Term Anxiety in Rats
}

\author{
James Lim', Miki Igarashi', Kwang-Mook Jung', Stefania Butini' ${ }^{2}$, Giuseppe Campiani ${ }^{2}$ and \\ Daniele Piomelli, ${ }^{*, 1,3,4,5}$
}

'Department of Anatomy and Neurobiology, University of California, Irvine, CA, USA; ${ }^{2}$ Dipartimento Farmaco Chimico Tecnologico, Università di Siena, Siena, Italy; ${ }^{3}$ Department of Pharmacology, University of Califormia, Invine, CA, USA; ${ }^{4}$ Department of Biological Chemistry, University of Califormia, Irvine, CA, USA; ${ }^{5}$ Drug Discovery and Development, Istituto Italiano di Tecnologia, Genova, Italy

\begin{abstract}
Individuals who experience life-threatening psychological trauma are at risk of developing a series of chronic neuropsychiatric pathologies that include generalized anxiety, depression, and drug addiction. The endocannabinoid system has been implicated in the modulation of these responses by regulating the activity of the amygdala and the hypothalamic-pituitary-adrenal axis. However, the relevance of this signaling complex to the long-term consequences of traumatic events is unclear. Here we use an animal model of predatory stress-induced anxiety-like behavior to investigate the role of the endocannabinoid system in the development of persistent anxiety states. Our main finding is that rats exposed to the fox pheromone 2,5-dihydro-2,4,5-trimethylthiazoline (TMT), a life-threatening stimulus for rodents, display a marked and selective increase in the mobilization of the endocannabinoid, 2-arachidonoyl-sn-glycerol (2-AG), in the amygdala. This effect lasts for at least 14 days after the stress has occurred. In addition, systemic or local pharmacological inhibition of monoacylglycerol lipase (MGL) - a lipid hydrolase that degrades 2-AG in presynaptic nerve terminals - elevates 2-AG levels and suppresses the anxiety-like behavior elicited by exposure to TMT. The results suggest that predator threat triggers long-term changes in 2-AG-mediated endocannabinoid signaling in the amygdala, and that pharmacological interventions targeting MGL might provide a therapeutic strategy for the treatment of chronic brain disorders initiated by trauma.

Neuropsychopharmacology (2016) 4I, I329-1339; doi: I0. I038/npp.20I5.284; published online 30 September 2015
\end{abstract}

\section{INTRODUCTION}

Traumatic life events heighten the risk of developing neuropsychiatric pathologies such as post-traumatic stress disorder (PTSD), substance abuse, and depression (Adshead and Ferris, 2007). In addition to being confronted with the intrusive re-experiencing of trauma-related memories, subjects with PTSD exhibit persistent anxiety states that greatly impair their quality of life (Brewin et al, 2000; Gmitrowicz and Kucharska, 1994; Kessler et al, 2005; Speckens et al, 2006). Our understanding of the neurobiology of anxiety provides a theoretical framework for the use of pharmacotherapy in the secondary prevention of chronic anxiety after life-threatening events (Davidson, 2004, 2006; Pitman and Delahanty, 2005). Evidence suggests that pharmacological agents such as $\beta$-adrenergic antagonists, opiates, D-cycloserine and anxiolytics are at least partially effective in managing the symptoms of PTSD (Ducrocq and Vaiva, 2005; Zatzick and Roy-Byrne, 2003; Zatzick and Roy-Byrne,

*Correspondence: Dr D Piomelli, Department of Anatomy and Neurobiology, University of California, Irvine, 3101 Gillespie Neuroscience Research Facility, Irvine, CA 92697-4625, USA, Tel: + I 949824 9179, Fax: + I 949824 6305,

E-mail: piomelli@uci.edu

Received 3 June 2015; revised 17 August 2015; accepted 31 August 2015; accepted article preview online II September 2015
2006; Zhang and Davidson, 2007). However, few studies have thoroughly examined the mechanisms of action and efficacy of psychotherapeutic drugs to prevent persistent anxiety states that develop in the aftermath of major trauma (Adshead and Ferris 2007; Davidson, 2004, 2006; Giuffrida et al, 2004; Pitman and Delahanty, 2005).

The endocannabinoid system is a signaling complex that consists of the G-protein-coupled receptors, cannabinoid receptor $1\left(\mathrm{CB}_{1}\right)$ and $\mathrm{CB}_{2}$, endogenous lipid-based ligands (mainly anandamide and 2-arachidonoyl-sn-glycerol, 2-AG), and proteins involved in the formation and deactivation of such ligands (Kano et al, 2009; Piomelli, 2003, 2014). Substantial evidence implicates the endocannabinoid system in the regulation of stress-coping responses (Bortolato et al, 2006; Gaetani et al, 2003; Hill et al, 2010; Kathuria et al, 2003; Lutz, 2009; Marsicano et al, 2002; Patel and Hillard, 2006, 2008; Steiner et al, 2008). Animal experiments suggest that activation of the endocannabinoid system contributes to stress-induced analgesia (Hohmann et al, 2005) and enhances stress-coping behaviors in mice and rats (Bortolato et al, 2007; Gobbi et al, 2005). Additional evidence indicates that anandamide produced in the amygdala modulates the response to acute stressful events (Gaetani et al, 2003; Gunduz-Cinar et al, 2013; Marsicano et al, 2002). Furthermore, exposure to an auditory fear-conditioning paradigm increases anandamide levels in the basolateral amygdala 
(BLA) of mice (Marsicano et al, 2002) and pharmacological inhibition of the anandamide-degrading enzyme, fatty acid amide hydrolase (FAAH), heightens stress-coping behaviors, and exerts anxiolytic-like and anti-depressant-like effects in rodents through a $\mathrm{CB}_{1}$-dependent mechanism (GunduzCinar et al, 2013; Hill et al, 2006; Kathuria et al, 2003).

Multiple studies have documented the existence of a link between the endocannabinoid system and the hypothalamicpituitary-adrenal (HPA) axis. Stressful stimuli activate neural inputs to the paraventricular nucleus of the hypothalamus, inducing the release of corticotropin-releasing hormone, which is then transported to the anterior pituitary gland and stimulates the release of adrenocorticotropic hormone (ACTH). Circulating ACTH initiates the release of cortisol (corticosterone in rodents) from the adrenal cortex (Pecoraro et al, 2006). Interestingly, disruption of $\mathrm{CB}_{1}$ receptors in the BLA increases HPA axis activity in nonstressed rats, elevating the plasma concentrations of corticosterone (Hill et al, 2010). Accordingly, local administration of an FAAH inhibitor in the BLA suppresses stressinduced activation of the HPA axis in a $\mathrm{CB}_{1}$-dependent manner (Hill et al, 2009). In addition, a human positron emission tomography study on PTSD patients revealed a significant upregulation of $\mathrm{CB}_{1}$ receptors within the amygdala-hippocampal-corticostriatal neural circuit associated with abnormally low levels of circulating anandamide (Neumeister et al, 2013). These data suggest that traumatic events can activate endocannabinoid signaling in the brain, which may act in turn as an intrinsic modulator of the response to such events. Indeed, FAAH inhibitors are currently under investigation as potential treatment for anxiety disorders and secondary prevention for PTSD (Finn, 2010). In addition to anandamide, changes in $2-A G$ have also been implicated in the regulation of stress-induced responses (Evanson et al, 2010; Hill et al, 2011; Sciolino et al, 2011; Sutt et al, 2008). However, a systematic investigation of the longterm impact of trauma-induced stress on 2-AG-mediated signaling is still lacking.

In the current study, we show that acute life-threatening stress in rats, ie, exposure to the red fox pheromone 2,5dihydro-2,4,5-trimethylthiazoline (TMT), selectively heightens 2-AG-mediated signaling in the amygdala, but not in the prefrontal cortex, hippocampus, striatum, hypothalamus, and cerebellum. We further show that systemic or intraamygdalar inhibition of monoacylglycerol lipase (MGL) activity suppresses anxiety-like behavior triggered by exposure to TMT, an effect prevented by $\mathrm{CB}_{1}$ receptor blockade. The results suggest that pharmacological strategies aimed at enhancing 2-AG signaling at $\mathrm{CB}_{1}$ receptors may offer a novel therapeutic approach to the treatment of pathological sequelae of psychological trauma, such as PTSD and substance abuse.

\section{MATERIALS AND METHODS}

\section{Animals}

We purchased male Sprague-Dawley rats (8-9 weeks, 225-250 g) from Charles River (Wilmington, MA) and housed them in groups of three per cage. We also used an in-house bred colony of C57BL6J mice (25-30 g). The animals were maintained on a 12 -h-light/dark cycle $(0630$ to 1830 hours) and received food (2020X, Harlan, Madison, WI) and water ad libitum. Animals undergoing surgery were individually housed and acclimated to laboratory conditions for 1 week before surgery. All procedures met the National Institutes of Health guidelines for the care and use of laboratory animals and were approved by the Institutional Animal Care and Use Committee of the University of California, Irvine.

\section{Chemicals}

We purchased TMT from Contech Enterprises (Delta, BC, Canada) and butyric acid from Aldrich (St Louis, MO). JZL184 was either purchased from Cayman Chemical (Ann Arbor, MI) or provided by the National Institute on Drug Abuse (NIDA). Rimonabant was supplied by NIDA and NF1819 was synthesized in the laboratory of G. Campiani.

\section{Drug Administration}

We dissolved rimonabant in a vehicle of propylene glycol/ Tween-80/sterile saline $(0.9 \%)(1 / 1 / 18, \mathrm{vol} / \mathrm{vol})$ and JZL184 in polyethylene glycol-400/Tween-80 (4/1). NF1819 was dissolved in $100 \%$ dimethyl sulfoxide (DMSO) for intraperitoneal (i.p.) injections and DMSO/sterile saline (1/39, $\mathrm{v} / \mathrm{v}$ ) for intracerebral infusions. We administered drugs and their vehicle by i.p. injection in a volume of $1 \mathrm{ml} / \mathrm{kg}$.

\section{Surgery}

We anesthetized the rats with ketamine $(100 \mathrm{mg} / \mathrm{kg}$, i.p., Phoenix Manufacturing Inc., Phoenix, AZ) and xylazine $(10 \mathrm{mg} / \mathrm{kg}$; Western Medical Supply, Arcadia, CA), given buprenorphine $(0.05 \mathrm{mg} / \mathrm{kg}$, i.p., Reckitt Benckiser, Slough, Berkshire, UK) to control pain and placed them in a stereotaxic frame (Kopf Instruments, Tujunga, CA) with the nose bar maintained at $-3.3 \mathrm{~mm}$ relative to the interaural line. In some experiments, we implanted two stainless-steel guide cannulae $(7.5 \mathrm{~mm} ; 23$ Gauge) bilaterally with the tips aimed at the BLA $(2.8 \mathrm{~mm}$ posterior and $5.0 \mathrm{~mm}$ lateral to bregma and $6.2 \mathrm{~mm}$ from the skull surface). In other experiments, we placed a single-guide cannula $(7.5 \mathrm{~mm}$; 23 Gauge) with the tip aimed at the third ventricle $(2.3 \mathrm{~mm}$ posterior to bregma and $6.5 \mathrm{~mm}$ from the skull surface). The cannulae were affixed to the skull with three anchoring screws and dental cement. Dummy cannulae $(7.5 \mathrm{~mm})$ were used to maintain patency. The coordinates were histologically verified by taking the flash frozen brain and mounting $20-\mu \mathrm{m}$ sections on slides and performing a cresyl violet stain (Sigma-Aldrich, St Louis, MO). Once the animal had recovered from anesthesia, a second dose of buprenorphine $(0.02 \mathrm{mg} / \mathrm{kg}$, i.p.) was administered. After surgery, the rats were individually housed and allowed to recover for 8 days before training and handling. The topical antibiotic, neosporin, was applied daily to prevent infections.

\section{Intracerebral Infusion}

We dissolved NF1819 in a vehicle of DMSO/sterile saline $(1 / 39, v / v)$. We infused individual doses of the drug into the BLA (5 ng, $0.2 \mu \mathrm{l})$ or the third ventricle $(75 \mathrm{ng}, 3 \mu \mathrm{l})$ using a $10-\mu l$ Hamilton syringe and a 30 -gauge injector (Plastics 
One, Chicago, IL) connected to the cannula via polyethylene tubing. The infusion needle extended $2 \mathrm{~mm}$ beyond the end of the guide cannula. An automated pump PHD 2000 (Harvard, Holliston, MA) drove the syringe at the rate of $0.1 \mu \mathrm{l} / \mathrm{min}$. The infusion needles were left in place for an additional $30 \mathrm{~s}$ to allow the solution to diffuse. Immediately following the procedure, the animals were returned to their home cages.

\section{Brain Tissue Preparation}

We excised brain regions of interest by taking micropunches from frozen brains mounted on a Microm HM525 cryostat (Thermo Fisher Scientific, Waltham, MA). The following brain regions were selected (coordinates, in millimeter from bregma; Paxinos and Watson, 1998): hypothalamus, single $2 \times 4 \mathrm{~mm}$ punch (from -0.8 to -4.8 ); amygdala, bilateral $2 \times 2 \mathrm{~mm}$ punch (from -1.6 to $-3.6 \mathrm{~mm}$ ); dorsal hippocampus, bilateral $2 \mathrm{~mm} \times 2 \mathrm{~mm}$ punch (from -1.6 to $-3.6 \mathrm{~mm}$ ); ventral hippocampus, bilateral $1.5 \times 2 \mathrm{~mm}$ punch (from -4.16 to $-6.16 \mathrm{~mm}$ ); cerebellum, single $2 \times 2 \mathrm{~mm}$ punch (from -10.3 to $-11.3 \mathrm{~mm}$ ). The punches were transferred to $8-\mathrm{ml}$ glass vials on dry ice and kept frozen at $-80^{\circ} \mathrm{C}$ until time of processing.

\section{Lipid Analyses}

We homogenized brain tissue samples (7-15 mg) in methanol (1 ml) containing deuterium-labeled 2-AG $(0.5 \mathrm{nmol})$ and anandamide $(10 \mathrm{pmol})$ as internal standards (Cayman, Ann Arbor, MI). We extracted lipids with chloroform $(2 \mathrm{ml})$ and water $(1 \mathrm{ml})$. The organic phases were dried under $\mathrm{N}_{2}$, reconstituted in chloroform $(2 \mathrm{ml})$ and fractionated by open-bed silica gel column chromatography as described (Fu et al, 2007). The eluted fractions containing 2-AG and anandamide were dried under $\mathrm{N}_{2}$, and residues were suspended in chloroform/methanol (1/3, vol/vol; $60 \mu \mathrm{l})$. Analyses were conducted using a liquid chromatography (LC) apparatus consisting of an Agilent 1100 system and 1946D mass spectrometer (MS) detector equipped with electrospray ionization interface (Agilent Technologies, Santa Clara, CA). Anandamide and 2-AG were separated on a ZORBAX Eclipse XDB-C18 column $(2.1 \times 100 \mathrm{~mm}$, $1.8 \mu \mathrm{m}$; Agilent Technologies) using an acetonitrile gradient. Solvent A consisted of water containing $0.1 \%$ formic acid, and solvent B consisted of acetonitrile containing $0.1 \%$ formic acid. We used the following gradient profile: $0-15$ $\min , 65 \% \mathrm{~B}$; $15-16 \mathrm{~min}, 65-100 \% \mathrm{~B}$ linear gradient; $16-26$ min, $100 \%$ B; 26-28 min, 100-65\% B linear gradient; 28-30 min, 65\% B. The column temperature was kept at $15^{\circ} \mathrm{C}$ and the flow rate at $0.3 \mathrm{ml} / \mathrm{min}$. ESI was in the positive ionization mode, capillary voltage was set at $3 \mathrm{kV}$, and the fragmentor voltage was set at $70 \mathrm{~V}$. Nitrogen gas was used as a drying gas at a flow rate of 13 liters per minute and a temperature of $350{ }^{\circ} \mathrm{C}$. The nebulizer pressure was set at 40 p.s.i. Absolute amounts of 2-AG and anandamide were quantified using a calibration curve.

\section{MGL Activity Assay}

We homogenized frozen brain samples in 10 volumes of icecold Tris- $\mathrm{HCl}$ (50 mM, pH 7.5) containing sucrose (0.32 M), centrifuged the homogenates at $1000 \mathrm{~g}$ for $10 \mathrm{~min}$, and incubated the supernatants $\left(0.1 \mathrm{mg}\right.$ of protein) at $37^{\circ} \mathrm{C}$ for $30 \mathrm{~min}$ in Tris- $\mathrm{HCl}(0.5 \mathrm{~mL})$ containing heptadecenoylglycerol $(10 \mu \mathrm{M}$; NuCheck Prep, Elysian, MN) as a substrate. Reactions were stopped by adding $1.5 \mathrm{ml}$ of chloroformmethanol (2/1) containing heptadecanoic acid (NuCheck Prep) as an internal standard. After centrifugation at $1000 \mathrm{~g}$ at $4{ }^{\circ} \mathrm{C}$ for $10 \mathrm{~min}$, we collected the organic layers, dried them under $\mathrm{N}_{2}$, suspended the residues in chloroform/methanol $(1 / 3,60 \mu \mathrm{l})$, and analyzed them by LC/MS (see above).

\section{Reverse Transcriptase-PCR and Quantitative PCR}

We extracted RNA from brain punches using a TRIzol (Invitrogen)/RNeasy (QIAGEN) hybrid protocol. Firststrand complementary DNAs were synthesized from $1 \mu \mathrm{g}$ of the total RNA using SuperScript II RNase $\mathrm{H}$ reverse transcriptase (Invitrogen) and oligo-dT12-18 primers, for $50 \mathrm{~min}$ at $42^{\circ} \mathrm{C}$. Quantitative PCR was conducted using Mx3000P system (Stratagene) by a TaqMan method. All mRNA levels were normalized using GAPDH (glyceraldehyde-3-phosphate dehydrogenase) as an internal standard. The primer/probe sets were as follows: for rat c-fos forward, 5'-TTCCGGCATCATCTAGGCC-3'; reverse, 5' -ACAGGTC CACATCTGGCACA-3'; TaqMan probe, 5'-AGTGGCTCG GAGACTGCCCGC-3'; for rat $\mathrm{CB}_{1}$ receptor forward, 5'-CA AGCACGCCAACAACACAG-3'; reverse, 5'-TCTTAACGG TGCTCTTGATGCA-3'; TaqMan probe, $5^{\prime}$-TGCACAGGGC CGCGGAGAG-3'. for rat diacylglycerol lipase- $\alpha$ (DGL- $\alpha$ ) forward, 5'-CCAGGCCTTTGGGCG-3'; reverse, 5'-GCCTA CCACAATCAGGCCAT-3'; TaqMan probe, 5'-ACCTGGG CCGTGGAACCAAACA-3'; for rat MGL forward, 5' -CCCA GTGGCACACCCAAG-3'; reverse, 5' -TAACGGCCACAGT GTTCCC-3'; TaqMan probe, 5'-CCCTCATCTTCGTGTCC CATGGAGC-3'. We used TaqMan gene expression assays for rat GAPDH (Rn01775763_g1; Life Technologies, Carlsbad, CA).

\section{Odor Exposure}

For 5 consecutive days, we handled each rat for $2 \mathrm{~min}$ and placed it for $10 \mathrm{~min}$ in a plastic exposure box $(45 \times 25 \times$ $20 \mathrm{~cm})$ containing a square of gauze $(5 \times 5 \mathrm{~cm})$ doused with saline $(35 \mu \mathrm{l})$. The box was housed in a fume hood. On the day of the experiment, we randomly assigned the animals to the saline or TMT group. The rats were placed for $10 \mathrm{~min}$ in the exposure box containing a gauze doused either with saline, TMT $(4.1 \mu \mathrm{M}, 35 \mu \mathrm{l})$, or butyric acid $(10.3 \mathrm{M}, 35 \mu \mathrm{l})$. After the procedure, the animals were immediately returned to their home cages.

\section{Elevated Plus Maze}

We conducted the behavioral tests between 0800 hours and 1400 hours. The elevated plus maze (EPM) apparatus included two open $(50 \times 10 \mathrm{~cm})$ and two closed $(50 \times 10 \times$ $40 \mathrm{~cm})$ arms extending from a central platform $(10 \times 10 \mathrm{~cm})$ elevated $60 \mathrm{~cm}$ above the floor. We placed each rat in the central platform of the maze, facing an open arm opposite to the experimenter, and videotaped test sessions of 5-min duration for each trial. Observers blinded to treatment measured the amount of time spent in the open arm, the 
number of open-arm entries, and the anxiety index. The latter was calculated as $1-$ (average of percent time in open arm and percent open-arm entry). Between tests the apparatus was cleaned with a $20 \%$ ethanol solution and was allowed to dry thoroughly. The open arms of the maze were illuminated at 150-170 lux, and the closed arms at 3040 lux.

\section{Experimental Design}

To determine the time course of the effects of TMT exposure, rats were habituated to the setting, exposed to saline or TMT, and then subjected to the EPM test $24 \mathrm{~h}, 7$ days, or 14 days following odor exposure. The rats were killed $3 \mathrm{~h}$ after the test and their brains were snap frozen. Regions of interest were collected from frozen brains and analyzed as described above. A separate group of rats was exposed to butyric acid and tested on the EPM $24 \mathrm{~h}$ later. Each animal was subjected to the test only once. In separate experiments, the rats were habituated to the experimental setting, exposed to saline, TMT, or butyric acid, and then killed at various time points $(30 \mathrm{~m}, 3 \mathrm{~h}, 1 \mathrm{~h}, 24 \mathrm{~h}, 7$ days, and 14 days) following odor exposure. The brains were removed and snap frozen. To test the effect of systemic MGL inhibition on TMT-induced longterm fear, the rats were habituated to the experimental setting and in addition to the handling procedure, received daily injections of vehicle (4:1 PEG-400:Tween-80, $1 \mathrm{ml} / \mathrm{kg}$, i.p) for 5 days. Eighteen hours after odor exposure, vehicle or JZL184 (16 mg/kg, i.p) was injected. Six hours or 6 days after JZL184 injections, the animals were subjected to the EPM test. In a separate group of rats, we administered the $\mathrm{CB}_{1}$ antagonist/inverse agonist, rimonabant ( $1 \mathrm{mg} / \mathrm{kg}$, i.p.), 30 min before JZL184 and performed an EPM test 6 days later. The rats were killed $3 \mathrm{~h}$ after the test and their brains were snap frozen for analyses. Last, we investigated the effect of MGL inhibition within the BLA or the hypothalamus. The rats were habituated to the experimental setting as outlined above. Eighteen hours after odor exposure, vehicle or NF1819 was infused into the BLA or the third ventricle and the EPM test was performed 6 days later. The animals were killed $3 \mathrm{~h}$ after the test and their brains were snap frozen for analyses.

\section{Statistical Analyses}

All results are presented as mean \pm SEM. Data were analyzed by two-way analysis of variance (ANOVA). Post hoc comparisons, when appropriate, were performed by Tukey's multiple comparisons test. In all cases, differences with a $P<0.05$ were considered significant. For all data, an extreme studentized deviate method with $\alpha=0.05$ was performed to identify significant outliers and removed from statistical analysis. TMT-resistant $v s$ TMT-sensitive animal groups were parsed out by calculating the k-means for each cluster and determining the center point.

\section{RESULTS}

\section{TMT Causes Long-Term Anxiety-Like Behavior in Rats}

We challenged male Sprague-Dawley rats with a single 10min exposure to the fox pheromone TMT (Fendt et al, 2005) and measured anxiety-like behavior in the EPM at various time points after odor exposure ( $24 \mathrm{~h}, 7$ days and 14 days). Compared with saline-exposed animals, rats challenged with TMT exhibited a statistically detectable increase in anxietylike behavior, which lasted for the entire duration of the experiment (14 days; Figure 1a-c). Exposure to TMT reduced the amount of time spent in the open arms of the maze (TMT effect, $\mathrm{F}_{1,42}=16.93, P=0.0002$; Figure 1a) and the number of open-arm entries (TMT effect, $\mathrm{F}_{1,42}=22.67$, $P<0.0001$; Figure $1 \mathrm{~b}$ ), and increased the anxiety index (TMT effect, $\mathrm{F}_{1,42}=21.17 \quad P<0.0001$; Figure $1 \mathrm{c}$ ). To verify the behavioral selectivity of the effect of TMT, we challenged a separate group of rats for $10 \mathrm{~min}$ with butyric acid, whose odor is pungent but non-threatening to rats. In contrast to TMT, exposure to butyric acid failed to induce EPM anxietylike responses $24 \mathrm{~h}$ after odor presentation (anxiety index: one-way ANOVA, $\mathrm{F}_{2,20}=13.68, P=0.0002$; Supplementary Table S1).

\section{Exposure to TMT Mobilizes 2-AG in the Amygdala}

To test whether exposure to TMT affects endocannabinoid signaling in the brain, we challenged rats with the odor and killed them $30 \mathrm{~min}, 3 \mathrm{~h}, 24 \mathrm{~h}, 7$ days, and 14 days later. Of the seven brain regions surveyed (Supplementary Table S2), two showed statistically detectable changes in 2-AG content, compared with saline-exposed controls: the amygdala, where 2-AG levels increased $24 \mathrm{~h}$ after TMT exposure and remained significantly elevated for the following 13 days (TMT effect $\mathrm{F}_{1,50}=20.26 \quad P<0.001$; time after odor $\mathrm{F}_{3,50}=4.62 P=0.003$; Figure $1 \mathrm{~d}$ ); and the hypothalamus, where a transient increase in 2-AG (3 h after TMT) was followed by a short-lasting decrease $(24 \mathrm{~h}$ after TMT; interaction $F_{1,50}=2.63, P=0.045$; Figure 1e). In addition to the 2-AG changes, mRNA analyses indicate an increase in c-Fos mRNA levels in the amygdala $24 \mathrm{~h}$ after TMT exposure, which returned to baseline levels 6 days later (time after odor, $\mathrm{F}_{1,23}=4.82 \quad P=0.038$; interaction, $\mathrm{F}_{1,23}=7.33 \quad P=0.013$; Figure 1f). We did not observe significant changes in the transcription of genes coding for $\mathrm{CB}_{1}$, (Figure 1g), MGL, and DGL- $\alpha$, a key enzyme of 2-AG production (Supplementary Figure S1a-f). No change in 2-AG mobilization was detected in the other brain regions included in the survey (Supplementary Table S3). In addition, anandamide levels in those regions were not affected by TMT under the present experimental conditions (Supplementary Table S4). Confirming the selectivity of the response to TMT, exposure to butyric acid had no effect on either 2-AG or anandamide levels (Supplementary Table S2).

Consistent with published data (Fendt et al, 2005; Holman et al, 2014), we found that $\sim 25 \%$ of the rats exposed to TMT did not develop long-term anxiety-like behavior. This led us to hypothesize that TMT exposure might differentially regulate 2-AG levels in resistant $v s$ sensitive rats. We applied the k-means cluster analysis to the 'ratio of time spent in the open-arm' data from TMT-exposed rats and determined the center of the clusters (TMT sensitive $v s$ TMT resistant) to be $14.3 \%$. Using this percentage as a threshold, we separated TMT-resistant $v s$ TMT-sensitive rats. In a separate experiment with 12 saline-exposed and 12 TMT-exposed animals, we parsed out eight TMT-resistant and four TMT-sensitive rats. As expected, the TMT-sensitive rats showed higher 


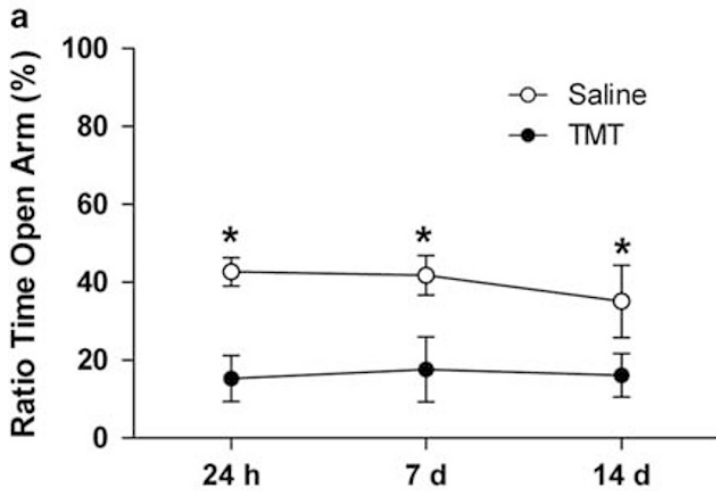

b
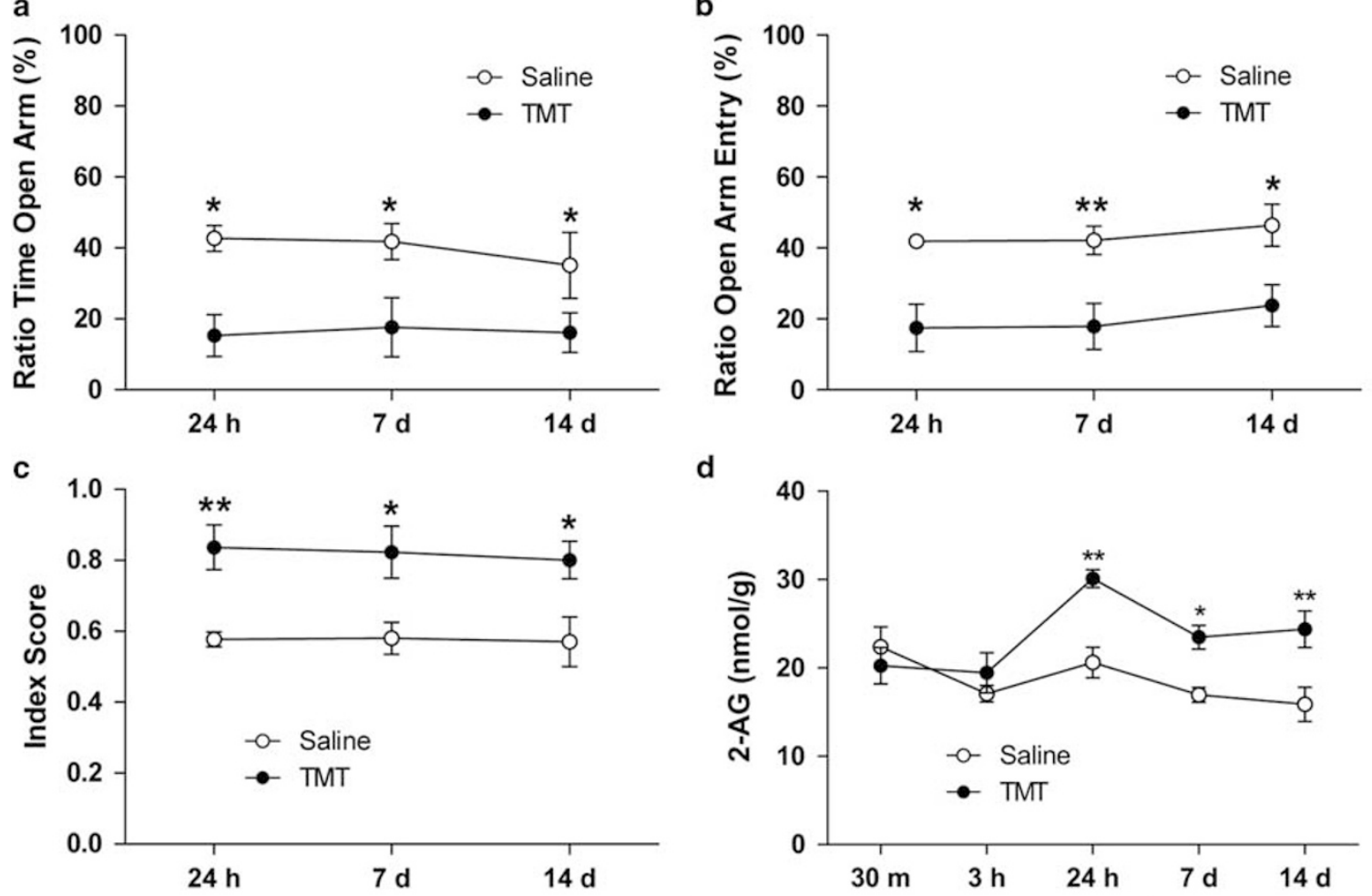

d
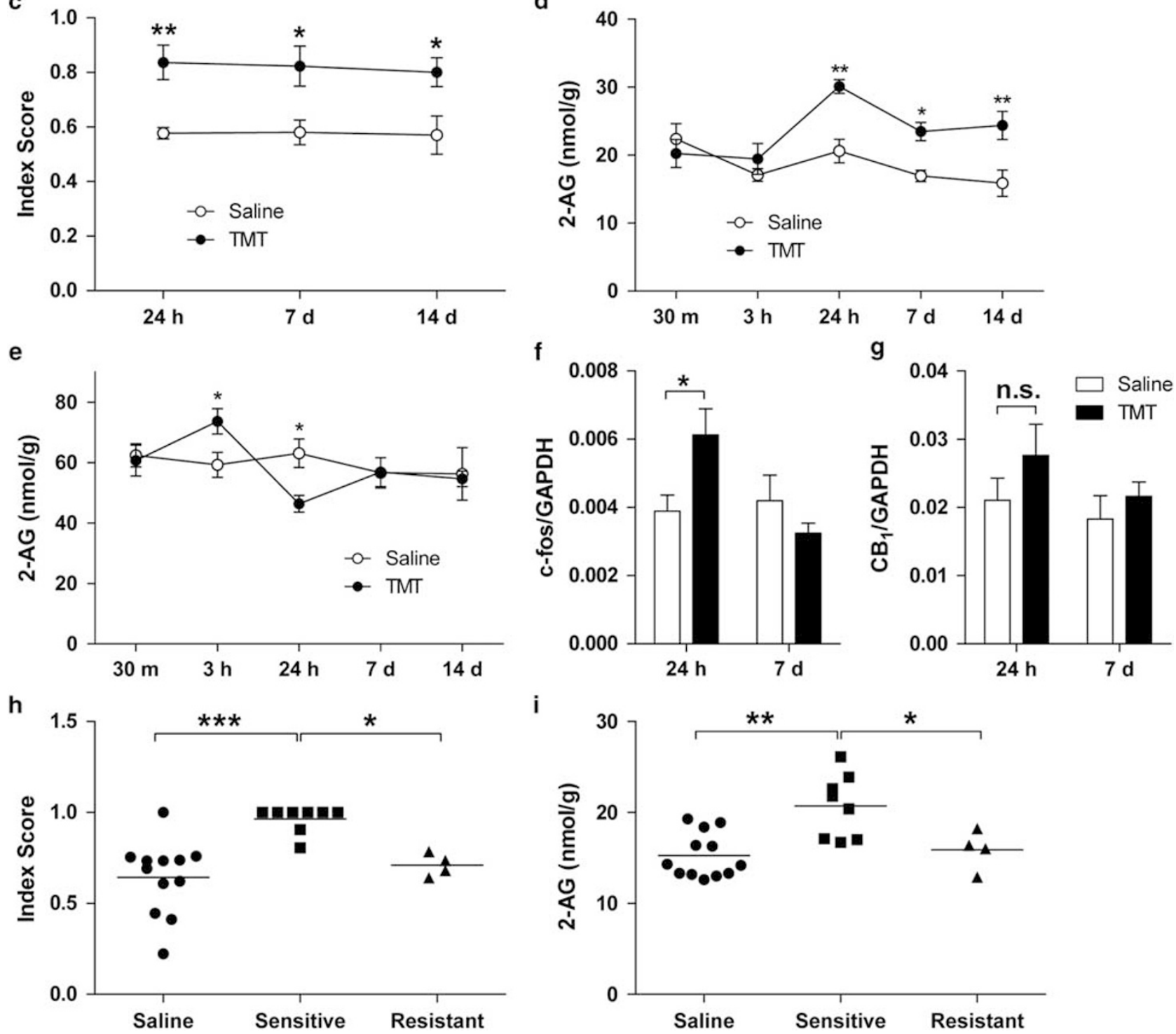

Figure I Rats exposed to TMT show significantly increased anxiety-like behavior and changes in 2-AG mobilization. (a-c) Rats were subjected to EPM $24 \mathrm{~h}$, 7 days, or 14 days after exposure to TMT. (a) Ratio of time in open arm, (b) ratio of open-arm entry, and (c) anxiety index indicate that exposure to TMT generates long-term anxiety in rats. The anxiety index was calculated as I - (average of percent time in open arm and percent open-arm entry) ( $n=8$ rats per group). (d) 2-AG content remained elevated in the amygdala for at least 14 days ( $n=6$ rats per group). (e) Fluctuations in 2-AG level were observed in the hypothalamus for the first $24 \mathrm{~h}(n=6$ rats per group). In addition to $2-A G$ content, (f) we observed an increase in c-fos mRNA expression in the amygdala at $24 \mathrm{~h}$ but (g) no significant change in $\mathrm{CB}_{1}$ receptor gene expression. The mRNA data are shown in relative quantity (copies) ratio to GAPDH as a normalizer ( $n=6-8$ rats per group). (h, i) We parsed out TMT-resistant and TMT-sensitive rats. (h) Anxiety index of TMT-resistant and TMT-sensitive rats indicates that TMT-sensitive rats show heightened level of anxiety-like behavior. (i) TMT-resistant did not exhibit increased levels of 2-AG 7 days after the TMT exposure. $N=4-12$ rats per group. Results are expressed as mean $\pm S E M$; $* P<0.05$, $* * P<0.0$ I, **** $P<0.00$ I. CB , cannabinoid receptor I; EPM, elevated plus maze; n.s., not significant; TMT, 2,5-dihydro-2,4,5-trimethylthiazoline. 
levels of anxiety-like behavior relative to TMT-resistant and saline-treated rats (one-way ANOVA, $\mathrm{F}_{2,21}=10.59$, $P=0.0007$; Figure $1 \mathrm{~h}$ ), which was associated with elevated 2-AG levels in the amygdala (Figure 1i). Compared with TMT-sensitive rats, TMT-resistant rats had 2-AG levels that were similar to those measured in saline-exposed control rats (one-way ANOVA, $F_{2,21}=9.29, P=0.0013$; Figure 1i).

\section{MGL Inhibition Prevents TMT-Induced Long-Term Anxiety-Like Behavior}

To examine the functional role of $2-\mathrm{AG}$ mobilization in the response to TMT exposure, we interrupted 2-AG degradation in vivo using the MGL inhibitor, JZL184 (Pan et al, 2009). A single injection of JZL184 (16 mg/kg, i.p.) decreased MGL activity (JZL184 effect, $\mathrm{F}_{1,20}=23.58 \quad P<0.0001$; Figure 2a) and increased 2-AG levels (JZL184 effect, $\mathrm{F}_{1,20}=11.46, P=0.0029$; Figure $2 \mathrm{~b}$ ) in the brain, irrespective of whether the rats were exposed to saline or TMT. As previously reported for other models of anxiety (Sciolino et al, 2011), treatment with the MGL inhibitor resulted in a reduction in anxiety-like behavior. Administration of JZL184 (16 mg/kg, i.p.) $18 \mathrm{~h}$ after TMT and $6 \mathrm{~h}$ before the tests normalized anxiety-like responses in TMT exposed, but not saline-exposed rats (TMT effect, $\mathrm{F}_{1,30}=14.72, P=0.0006$; JZL184 effect, $\mathrm{F}_{1,30}=9.89 P=0.0037$; interaction, $\mathrm{F}_{1,30}=$ 10.18, $P=0.0033$; Figure 2c).

Next, we tested whether an early intervention with the MGL inhibitor might influence the subsequent development of long-lasting TMT-induced anxiety-like responses. We administered JZL184 (i.p.) $18 \mathrm{~h}$ after TMT exposure followed by behavioral tests 6 days later. We found that JZL184 reduced anxiety-like responses in TMT exposed, but not saline-exposed rats (TMT effect, $F_{1,42}=11.66, P=0.0014$; JZL184 effect, $\mathrm{F}_{1,42}=5.61, P=0.023$; interaction, $\mathrm{F}_{1,42}=$ 6.138, $P=0.017$; Figure 2d). As expected, MGL activity (JZL184 effect, $\mathrm{F}_{1,20}=0.34, P=0.57$; Figure 2e) and amygdalar 2-AG content (JZL184 effect, $F_{1,20}=0.28, \quad P=0.6$; Figure 2f) were at basal levels 6 days after administration of the drug. The results suggest that temporary enhancement of 2-AG-mediated signaling is sufficient to prevent long-term behavioral changes evoked by predator stress.

\section{The Anxiolytic-Like Effect of JZL184 is $\mathrm{CB}_{1}$ Receptor Dependent}

Next, we examined whether the long-term effect of JZL184 might be due to 2-AG-mediated activation of $\mathrm{CB}_{1}$ receptors. First, we tested whether the $\mathrm{CB}_{1}$ inverse agonist, rimonabant, has a direct effect on TMT-induced anxiety-like behavior. We administered the drug $(1 \mathrm{mg} / \mathrm{kg}$, i.p.) $17.5 \mathrm{~h}$ after TMT exposure and tested the behavior after 6 days. The treatment did not affect the time spent in the open arm (TMT effect $\mathrm{F}_{1,18}=9.24, P=0.007$; rimonabant effect $\mathrm{F}_{1,18}=0.022$, $P=0.88$; Figure $3 \mathrm{a}$ ), the number of open-arm entries (TMT effect $\mathrm{F}_{1,18}=4.88, P=0.04$, rimonabant effect $\mathrm{F}_{1,18}=0.077$, $p=0.78$; Figure $3 \mathrm{~b}$ ), or the anxiety index (TMT effect, $\mathrm{F}_{1,18}=7.87, \quad P=0.012$, rimonabant effect, $\mathrm{F}_{1,18}=0.054$, a

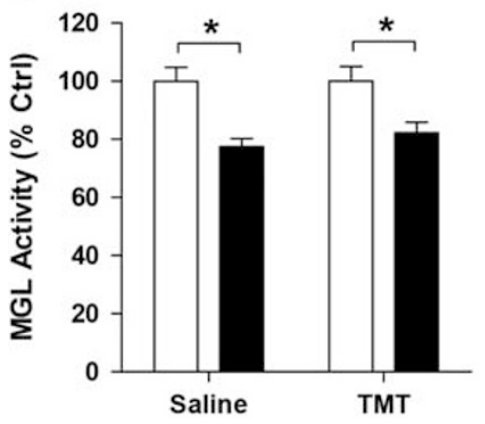

d

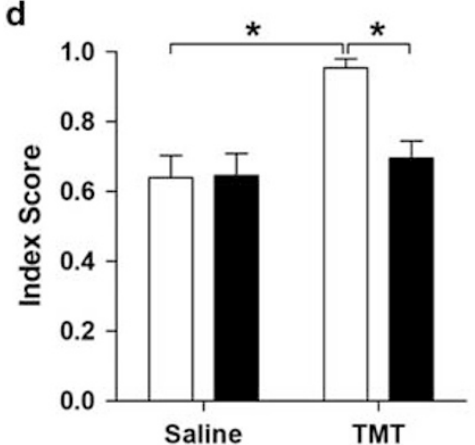

b

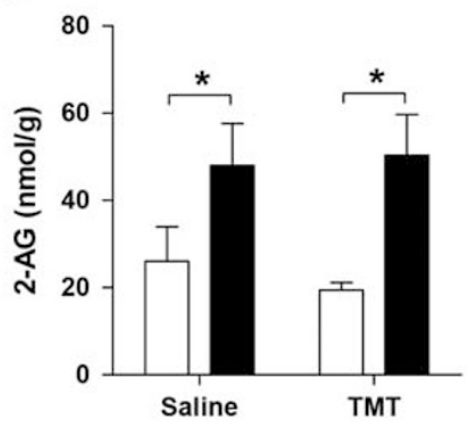

e

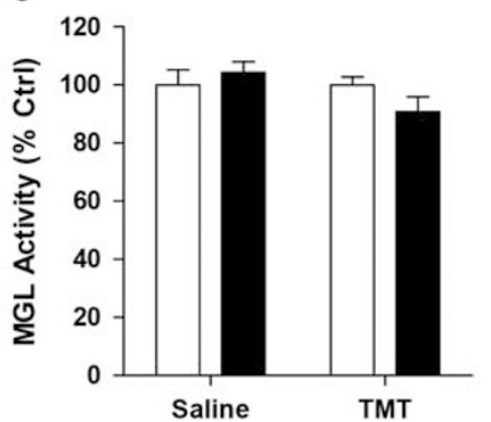

c

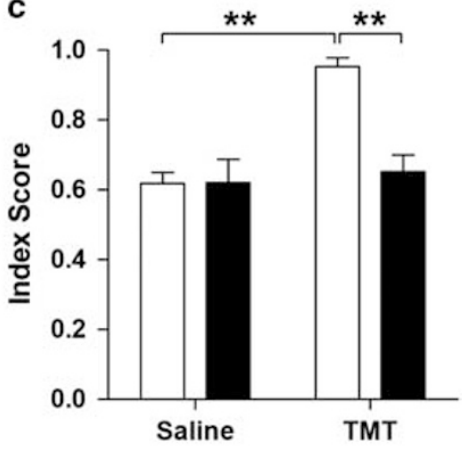

f

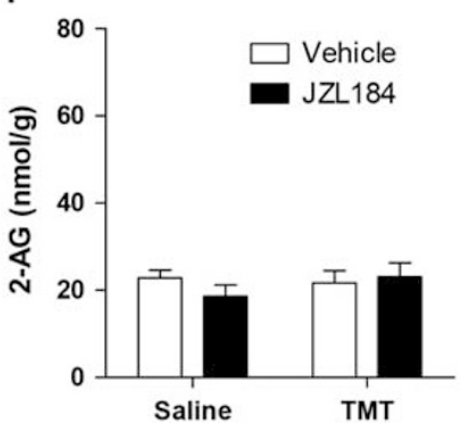

Figure 2 A single administration of MGL inhibitor, IZL I 84, exerts anxiolytic-like effects in TMT-exposed rats. (a-c) Acute, single i.p. injection of JZLI 84 I 8 h after TMT exposure followed by behavioral tests after $6 \mathrm{~h}$ exerts an anxiolytic-like effect. (a) JZLI84 (i.p.) administration inhibits brain MGL activity and (b) increases 2-AG content after $6 \mathrm{~h}$ ( $n=6$ rats per group). (c) Anxiety index data ( $n=8-9$ rats per group). (d) Administration of JZLI 84 (i.p.) I $8 \mathrm{~h}$ after TMT exposure, followed by behavioral tests 7 days post-TMT exposure reduces anxiety-like responses in rats $(n=1|-| 2)$. (e-f) JZLI 84 (i.p.) administration 6 days before measurement causes no change in brain (e) MGL activity or ( $f$ ) $2-A G$ content ( $n=6$ rats per group). Results are expressed as mean $\pm S E M$; $* P<0.05$, *** $P<0.0$ I. i.p., intraperitoneal; MGL, monoacylglycerol lipase; TMT, 2,5-dihydro-2,4,5-trimethylthiazoline. 

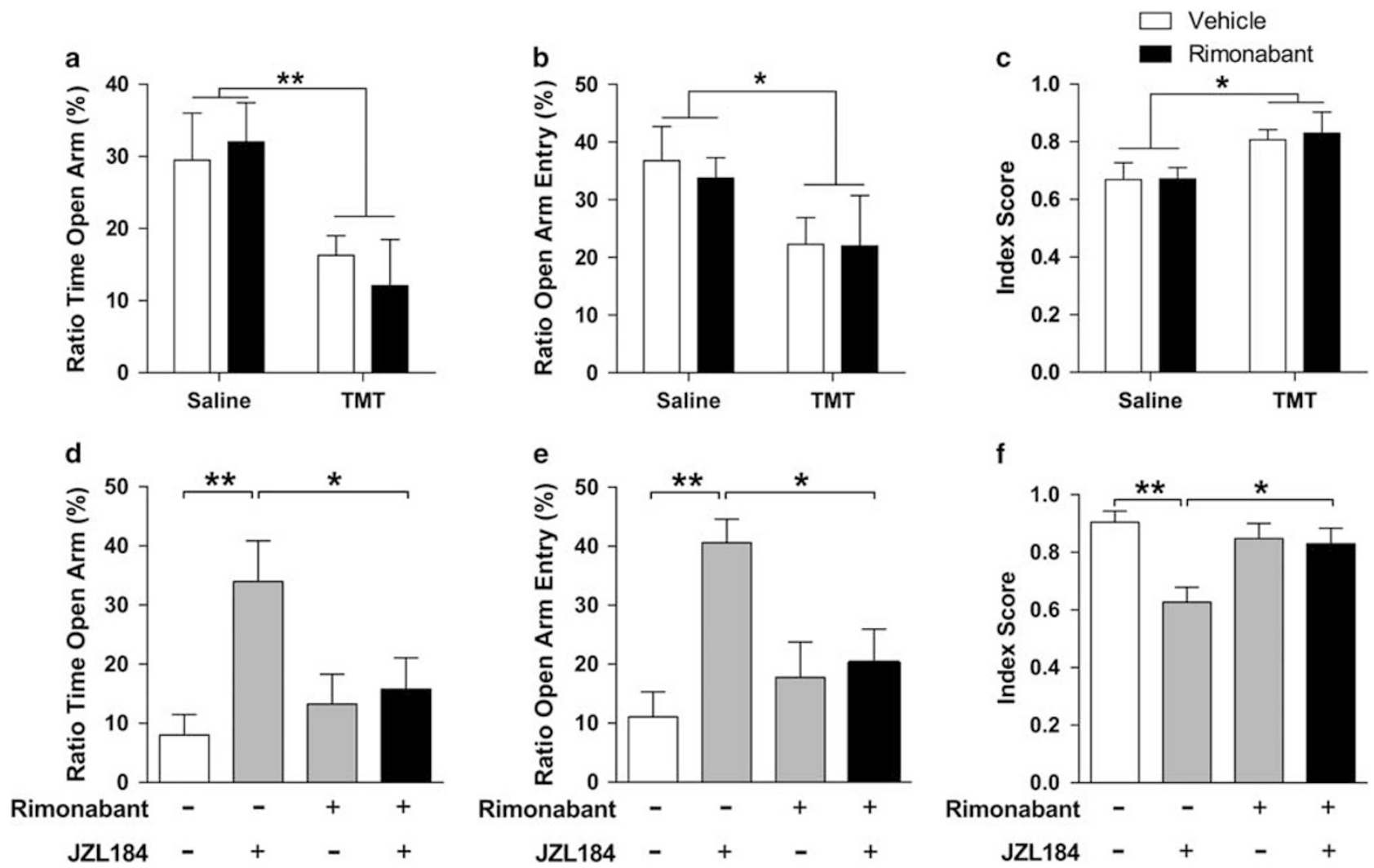

Figure 3 The anxiolytic-like effects of JZLI84 are $C B_{1}$ dependent. (a-c) Intraperitoneal injection of rimonabant 17.5 h after TMT exposure causes no significant behavioral changes. (a) Ratio of time spent in open arm, (b) ratio of open-arm entry, and (c) anxiety index indicate that rimonabant (I mg/kg) administration $18 \mathrm{~h}$ after TMT exposure has no effect on EPM behavior 7 days later ( $n=5-6$ rats per group). ( $\mathrm{d}-\mathrm{f}$ ) Intraperitoneal injection of rimonabant $30 \mathrm{~min}$ before a single JZL I 84 injection I $8 \mathrm{~h}$ after TMT exposure blocks the anxiolytic-like effect of JZL I 84 that lasts for at least 7 days. (d) Ratio of time spent in open arm, (e) ratio of open-arm entry, and ( $f$ ) anxiety index indicate that the anxiolytic-like effects of JZLI 84 are CB, dependent ( $n=1 \mid-12$ rats per group). Results are expressed as mean $\pm \mathrm{SEM}$; $* P<0.05$, **P<0.0I. $C B_{1}$, cannabinoid receptor I; EPM, elevated plus maze; TMT, 2,5-dihydro-2,4,5trimethylthiazoline.

$P=0.82$; Figure $3 c$ ) of rats exposed either to saline or TMT. In another group of rats, we administered rimonabant ( $1 \mathrm{mg} / \mathrm{kg}$, i.p.) $17.5 \mathrm{~h}$ after TMT exposure (all rats were exposed to TMT), followed by JZL184 injection after $30 \mathrm{~min}$ and behavioral testing after 6 days. Rimonabant suppressed the anxiolytic-like effects of JZL184 (ratio time open arm: interaction, $\mathrm{F}_{1,43}=4.85, P=0.033$; ratio entry open arm: interaction, $\mathrm{F}_{1,43}=6.13, P=0.017$; anxiety index: interaction, $\mathrm{F}_{1,43}=6.85, P=0.012$; Figure $3 \mathrm{~d}-\mathrm{f}$ ), providing evidence that that such effect requires $\mathrm{CB}_{1}$ receptor activation.

\section{MGL Inhibition in the BLA Blocks TMT-Induced Anxiety-Like Behavior}

To further explore the mechanism underlying the anxiolyticlike effect of MGL inhibition, we examined whether the amygdala or the hypothalamus, in each of which 2-AG levels change in response to TMT, is responsible for the suppression of TMT-induced anxiety-like behavior. Because JZL184 is poorly soluble, we used a newly disclosed compound, NF1819, which is a potent, selective, and watersoluble MGL inhibitor. The synthesis and general properties of this agent will be reported elsewhere.

To test the efficacy of NF1819, we first administered the drug systemically to adult male mice $(5 \mathrm{mg} / \mathrm{kg}$, i.p.). We found that NF1819 markedly reduces MGL activity $(P<0.0001)$ and increases $2-A G$ content $(P<0.0001)$ in brain tissue within $1 \mathrm{~h}$ of administration (Figure $4 \mathrm{a}$ and $\mathrm{b}$ ). We then infused NF1819 either into the BLA or the third ventricle of rats (Figure $4 \mathrm{c}$ and $\mathrm{f}$ ). Compared with vehicle, MGL activity was decreased and 2-AG levels were increased in BLA micropunches (MGL activity: $P=0.045 ; 2-A G$ levels: $P=0.0007$; Figure $4 \mathrm{~d}$ and e; micropunch A), but not in micropunches taken from immediately adjacent brain regions (Figure $4 \mathrm{~d}$ and e; micropunches B and C). Similarly, infusion of NF1819 into the third ventricle resulted in significant changes in both MGL activity and 2-AG accumulation (MGL activity: $P=0.027$; 2-AG levels: $P=0.0008$; Figure $4 \mathrm{~g}$ and $\mathrm{h}$ ).

Having confirmed that NF1819 effectively inhibits MGL activity and accrues 2-AG availability after intracerebral administration, we targeted the BLA or the hypothalamus for behavioral testing. We first exposed all the rats to TMT and then infused NF1819 (5 ng, $0.2 \mu \mathrm{l}$ ) into the BLA $18 \mathrm{~h}$ after TMT exposure and 6 days before the behavioral tests. NF1819 reduced anxiety-like responses in rats, compared with vehicle $(P=0.0045$ Figure $5 \mathrm{a})$. In contrast, infusion of NF1819 into the third ventricle $(75 \mathrm{ng}, 3 \mu \mathrm{l}) 18 \mathrm{~h}$ after TMT exposure and 6 days before the behavioral tests had no significant changes in EPM behavior $(P=0.82$; 


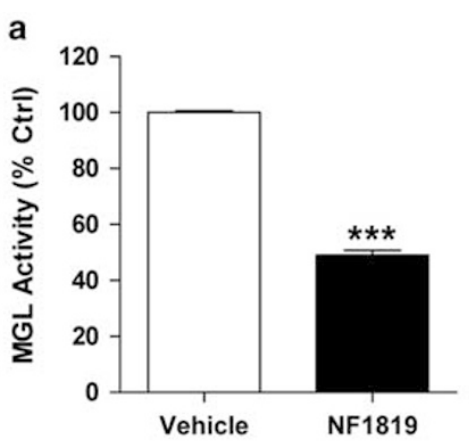

c

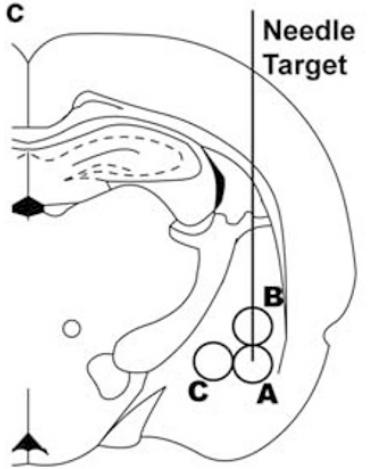

f

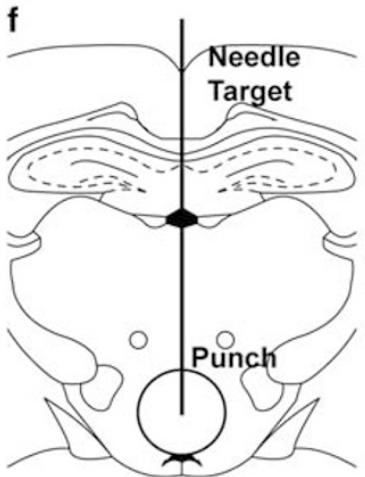

d

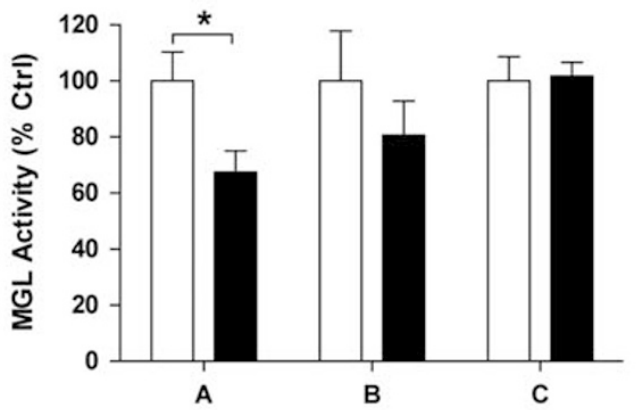

g

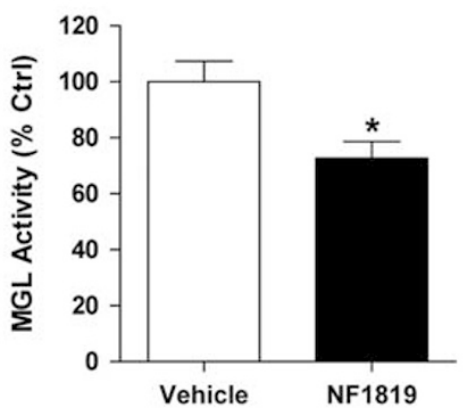

b

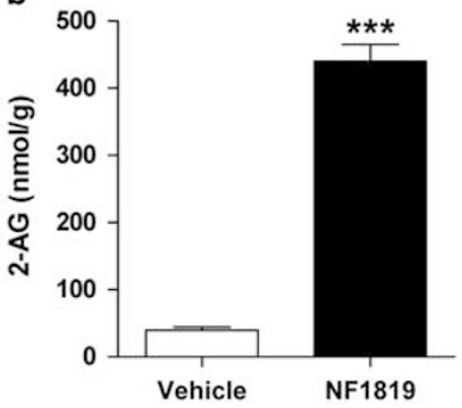

e

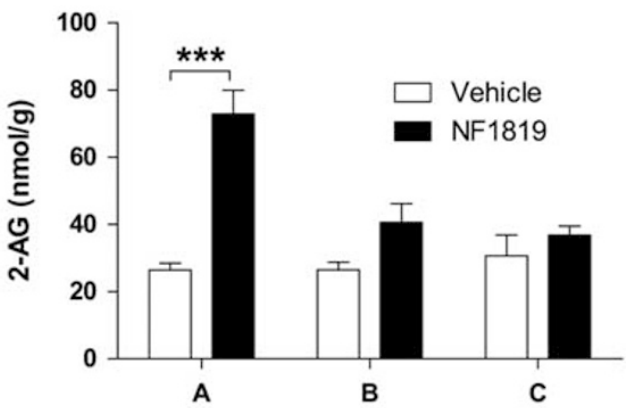

h

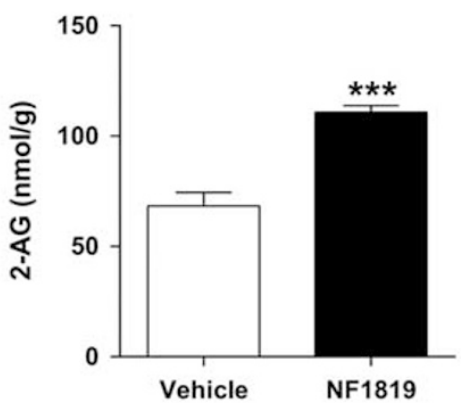

Figure 4 Effects of NFI8I9 on MGL activity and 2-AG mobilization. (a) Intraperitoneal injection of NFI8I9 (5 mg/kg) lowers rat MGL activity and (b) increases 2-AG content in mouse brain. (c-e) Infusion of NFI8I9 into the BLA inhibits local MGL activity and increases 2-AG level. (c) Diagram of the needle tract and location of brain punches taken to measure MGL activity and 2-AG levels in the amygdala. (d) NFI8I9 infusion into the BLA inhibits MGL activity and (e) increases 2-AG levels at the site of injection (A) but not in nearby tissue (B-C; $n=4$ rats per group). ( $\mathrm{f}-\mathrm{h}$ ) Infusion of NFI8I9 into the third ventricle inhibits MGL activity and increases 2-AG level in the hypothalamus. ( $f$ ) Diagram of the needle tract and location of brain punches taken to measure MGL activity and 2-AG levels in the hypothalamus. (g) NFI8I9 infusion into the third ventricle inhibits MGL activity and (h) increases 2-AG levels in the hypothalamus ( $n=4$ rats per group). Results are expressed as mean $\pm S E M ; * P<0.05$, **** $P<0.00$ I. BLA, basolateral amygdala; MGL, monoacylglycerol lipase.

Figure $5 \mathrm{~d}$ and $\mathrm{f}$ ). The results suggest that the anxiolytic-like effects of MGL blockade are mediated through the BLA.

\section{DISCUSSION}

In this study, we report that the long-term anxiety-like state caused in rats by exposure to the fox pheromone TMT is paralleled by a sustained elevation in amygdalar levels of the endocannabinoid 2-AG. We further show that pharmacological inhibition of the 2-AG-hydrolyzing enzyme, MGL, increases 2-AG accumulation and produces marked anxiolytic-like effects, which are abrogated by the $\mathrm{CB}_{1}$ cannabinoid receptor antagonist, rimonabant. The amygdala appears to be critical to this response because local infusion of an MGL inhibitor into this structure recapitulates the actions of systemic MGL blockade. Last, inhibiting MGL within $24 \mathrm{~h}$ of exposure to TMT completely prevents the development of long-term anxiety-like behavior. The results suggest that 2-AG mobilization in the amygdala acts as an intrinsic feedback mechanism that protects rats against the chronic consequences of TMT-evoked stress.

An extensive body of research has established that stressful sensory information across multiple modalities enters the amygdala through the BLA and the centrolateral amygdala (CeAL), both of which project to the centromedial amygdala (CeAM; LeDoux, 2000). The CeAM, in turn, projects to rostral and caudal brain regions such as the hypothalamus, 

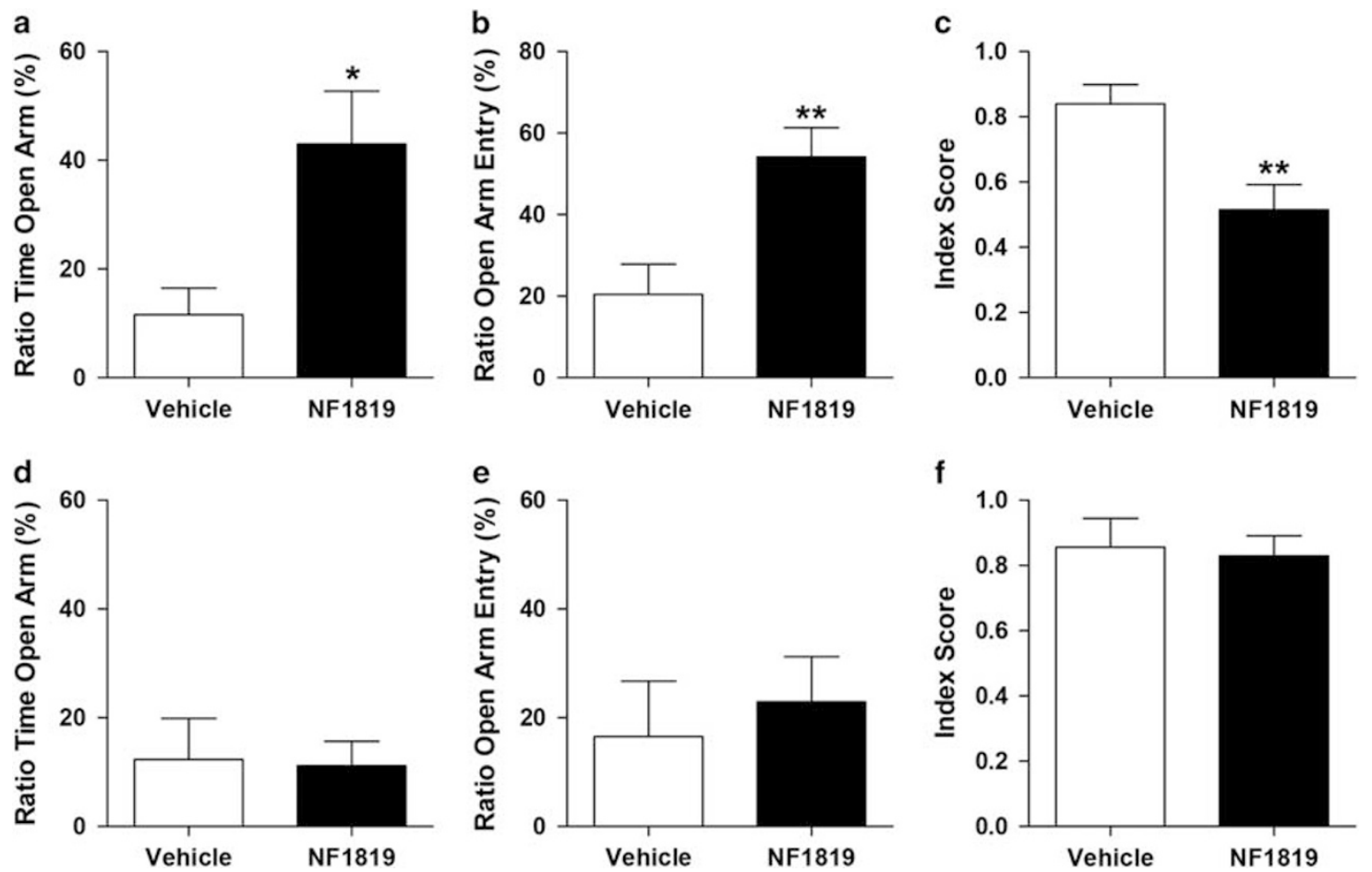

Figure 5 The anxiolytic-like effects of MGL inhibition on TMT-induced anxiety-like behavior are mediated by the BLA. (a-c) Infusion of NFI8I9 into the BLA $18 \mathrm{~h}$ after TMT exposure has an anxiolytic-like effect that lasts for at least 7 days. (a) Ratio of time spent in open arm, (b) ratio of open-arm entry, and (c) anxiety index suggest that the anxiolytic-like effects of the MGL inhibitor occur in the BLA. (d-f) Infusion of NFI8I9 into the third ventricle has no overt behavioral effect in TMT-exposed rats. (d) Ratio of time spent in open arm, (e) ratio of open-arm entry, and ( $f$ ) anxiety index ( $n=5$ per group). Results are expressed as mean $\pm \mathrm{SEM} ; n=6-10$ rats per group; $* P<0.05$, **P $<0.01$. BLA, basolateral amygdala; MGL, monoacylglycerol lipase; TMT, 2,5-dihydro2,4,5-trimethylthiazoline.

involved in the expression of stress, fear, and anxiety (LeDoux, 2000). Functional studies have shown that direct activation of CeAL strongly inhibits CeAM output neurons through GABA (gamma-aminobutyric)-ergic projections and reduces fear and anxiety responses, whereas direct activation of the BLA increases fear and anxiety responses through glutamatergic projections to the CeAM (Etkin et al, 2009; Li et al, 2013). Because $\mathrm{CB}_{1}$ receptor expression in the amygdala is restricted to the BLA (Ramikie and Patel, 2012), it is tempting to hypothesize that the persistent increase in amygdalar 2-AG mobilization after TMT exposure provides a negative feedback signal that inhibits the BLA and attenuates CeAM activation. In addition, although infusion of NF1819 into the third ventricle caused no behavioral effect, the changes of 2-AG levels in this region after TMT exposure are suggestive of a link between hypothalamus and amygdala in the modulation of fear and anxiety. Identifying the precise neural mechanism underlying 2-AG mobilization is an important question that needs to be addressed by future studies.

Previous reports indicate that anandamide has a protective role in the response to environmental stressors (Hill et al, 2013; Hill et al, 2011; Kathuria et al, 2003; Patel and Hillard, 2006) and that stressful stimuli enhance anandamide mobilization in brain regions such as BLA and prefrontal cortex (Bortolato et al, 2006; Gaetani et al, 2003; Kathuria et al, 2003; Lutz, 2009; Marsicano et al, 2002; Patel and Hillard, 2006, 2008; Steiner et al, 2008). In the auditory fear-conditioning paradigm, administration of FAAH inhibitors into the BLA enhances fear extinction and impairs fear memory retrieval
(Gunduz-Cinar et al, 2013; Marsicano and Lutz, 2006; Marsicano et al, 2002). How do anandamide and 2-AG cooperate to modulate the response to stress? Although the available data do not allow us to answer this question, it is interesting to note that previous studies have reported a temporal disconnect between the mobilization of anandamide and that of 2-AG. For example, foot shock induces a rapid and short-lived increase in 2-AG content in the dorsal midbrain of rats, which is accompanied by a slower, more sustained increase in anandamide levels (Hohmann et al, 2005). The lack of changes in anandamide levels observed in the present study, compared with those previously documented (Hill et al, 2009; Pecoraro et al, 2006), might be explained by differences in the time course of mobilization of the two endocannabinoid transmitters in the amygdala. Relevant to this point, a recent study has shown that acute activation of muscarinic acetylcholine receptors in the amygdala causes a short-lived form of anandamide-mediated synaptic depression, whereas prolonged activation $(>1 \mathrm{~h})$ of the same receptor causes a tonic 2-AG-mediated depression (Ramikie et al, 2014). On the basis of those data, it is tempting to speculate that short-term changes in anandamide mobilization might have a role in acute stress-coping responses, whereas 2-AG might be involved in the sustained response to a stressor.

The anxiolytic-like effects elicited by MGL blockade, and their sensitivity to rimonabant, suggest that endogenously produced 2-AG is involved in the regulation of TMTinduced long-term anxiety through the activation of $\mathrm{CB}_{1}$ receptors in the BLA. These findings complement a growing body of evidence suggesting a role for $2-\mathrm{AG}$ in the 
modulation of emotional responses to stress (Evanson et al, 2010; Hill et al, 2011; Sciolino et al, 2011; Sutt et al, 2008). For example, studies have shown that cat odor exposure causes rapid changes in the expression of enzymes involved in the biosynthesis and degradation of $2-A G$ in various rat brain regions, including amygdala and periaqueductal gray area, immediately after odor exposure (Sutt et al, 2008). These studies did not examine the long-term consequences of odor exposure, which were the object of the present investigation. In addition, it has been reported that systemic administration of JZL184 reduces anxiety-like behaviors in rats in a $\mathrm{CB}_{1}$-dependent manner, but only when the animals are exposed to high-stress conditions (ie, strong environmental light) (Sciolino et al, 2011). In agreement with this evidence, the current work suggests that 2-AG acts as an endogenous modulator of anxiety-like behavior, and that this action might be particularly relevant during conditions of high stress.

Exposure to TMT evokes a prolonged anxiety-like state that is paralleled by an increase in 2-AG levels within the amygdala. A single intra-BLA administration of NF1819 $18 \mathrm{~h}$ after TMT exposure evoked anxiolytic-like effects 7 days after the exposure. This suggests that enhancing the mobilization of endogenous $2-\mathrm{AG}$ protects rats against an inappropriately severe response to a life-threatening stressor. The persistent increase in 2-AG content after TMT exposure may be a consequence of temporary increase in neuronal activity in specific sets of synapses feeding into the BLA from higher brain regions involved in the stress response. Consistent with this view, we observed a significant increase in amygdalar c-Fos mRNA expression $24 \mathrm{~h}$, but not 7 days after TMT exposure. One possibility is that MGL in the BLA modulates neurotransmission between specific synapses engaged in 2-AG signaling, thus destabilizing essential connections and promoting long-term anxiety. Conversely, it is also possible that synapses that are not engaged in 2-AGmediated signaling might be responsible for triggering the long-term anxiety-like state in rats, and the 2-AG-engaged synapses prevent over-activation of this circuit. Therefore, elevated 2-AG content in unengaged synapses may destabilize and silence all communications from the BLA. This is plausible as other studies show that increase of endocannabinoid activity can drive $\mathrm{CB}_{1}$-dependent synaptic depression in the amygdala (Gunduz-Cinar et al, 2013; Ramikie et al, 2014). Further investigations are necessary to determine the molecular mechanism(s) of 2-AG mobilization and its relation to long-term anxiety responses.

Not all people respond to a traumatic event in the same way (Adshead and Ferris 2007; Davidson, 2004, 2006; Giuffrida et al, 2004; Pitman and Delahanty, 2005). Studying individual differences that influence post-trauma adaptation may generate clues about how anxiety states are triggered. Consistent with published data, 25\% of TMT-exposed rats in our study failed to develop long-term anxiety-like behavior in the EPM (Fendt et al, 2005; Holman et al, 2014). In addition, TMT-resistant rats did not exhibit elevated levels of 2-AG in the amygdala compared with TMT-sensitive animals. This suggests that the persistent increase in 2-AG content in TMT-sensitive animals may serve as a natural coping mechanism to an overwhelming stressor. For TMT-resistant animals, the TMT exposure alone may not have been adequate enough to trigger a significant fear to activate a 2-AG-mediated-coping response. Further investigation of the difference in endocannabinoid regulation between TMT-resistant and TMT-sensitive rats should provide valuable insights into the mechanisms underlying the induction of long-term anxiety states.

In conclusion, our study suggests that exposure to predator odor initiates changes in amygdalar 2-AG signaling, which might have a modulatory/protective role in the response to a traumatic event. The results further suggest that pharmacological agents that enhance $2-A G$ signaling may attenuate anxiety-like responses in stressed animals and anxiety symptoms in human trauma victims.

\section{ACKNOWLEDGMENTS}

We thank Paulina Tapia, Varsha Pandey, Ramin Chisaz, and Jennifer Daglian for help with experiments. We thank Conor Cox for help with statistics.

\section{FUNDING AND DISCLOSURE}

The work in the Piomelli lab was supported by the National Institute of Drug Abuse, grants number DA-031387 and DA-037752. The authors declare no conflict of interest.

\section{REFERENCES}

Adshead G, Ferris S. (2007). Treatment of victims of trauma. Adv Psychiatr Treat 13: 358-368.

Bortolato M, Campolongo P, Mangieri RA, Scattoni ML, Frau R, Trezza V et al (2006). Anxiolytic-like properties of the anandamide transport inhibitor AM404. Neuropsychopharmaco$\log y$ 31: 2652-2659.

Bortolato M, Mangieri RA, Fu J, Kim JH, Arguello O, Duranti A et al (2007). Antidepressant-like activity of the fatty acid amide hydrolase inhibitor URB597 in a rat model of chronic mild stress. Biol Psychiatry 62: 1103-1110.

Brewin CR, Andrews B, Valentine JD (2000). Meta-analysis of risk factors for posttraumatic stress disorder in traumaexposed adults. J Consult Clin Psychol 68: 748-766.

Davidson JR (2004). Long-term treatment and prevention of posttraumatic stress disorder. J Clin Psychiatry 65(Suppl 1): 44-48.

Davidson JR (2006). Pharmacologic treatment of acute and chronic stress following trauma: 2006. J Clin Psychiatry 67(Suppl 2): 34-39.

Ducrocq F, Vaiva G (2005). [From the biology of trauma to secondary preventive pharmalogical measures for post-traumatic stress disorders]. Encephale 31: 212-226.

Etkin A, Prater KE, Schatzberg AF, Menon V, Greicius MD (2009). Disrupted amygdalar subregion functional connectivity and evidence of a compensatory network in generalized anxiety disorder. Arch Gen Psychiatry 66: 1361-1372.

Evanson NK, Tasker JG, Hill MN, Hillard CJ, Herman JP (2010). Fast feedback inhibition of the HPA axis by glucocorticoids is mediated by endocannabinoid signaling. Endocrinology 151: 4811-4819.

Fendt M, Endres T, Lowry CA, Apfelbach R, McGregor IS (2005). TMT-induced autonomic and behavioral changes and the neural basis of its processing. Neurosci Biobehav Rev 29: 1145-1156.

Finn DP (2010). Endocannabinoid-mediated modulation of stress responses: physiological and pathophysiological significance. Immunobiology 215: 629-646.

Fu J, Astarita G, Gaetani S, Kim J, Cravatt BF, Mackie K et al (2007). Food intake regulates oleoylethanolamide formation and degradation in the proximal small intestine. J Biol Chem 282: 1518-1528. 
Gaetani S, Cuomo V, Piomelli D (2003). Anandamide hydrolysis: a new target for anti-anxiety drugs? Trends Mol Med 9: 474-478.

Giuffrida A, Leweke FM, Gerth CW, Schreiber D, Koethe D, Faulhaber J et al (2004). Cerebrospinal anandamide levels are elevated in acute schizophrenia and are inversely correlated with psychotic symptoms. Neuropsychopharmacology 29: 2108-2114.

Gmitrowicz A, Kucharska A (1994). [Developmental disorders in the fourth edition of the American classification: diagnostic and statistical manual of mental disorders (DSM IV - optional book)]. Psychiatr Pol 28: 509-521.

Gobbi G, Bambico FR, Mangieri R, Bortolato M, Campolongo P, Solinas $\mathrm{M}$ et al (2005). Antidepressant-like activity and modulation of brain monoaminergic transmission by blockade of anandamide hydrolysis. Proc Natl Acad Sci USA 102: 18620-18625.

Gunduz-Cinar O, MacPherson KP, Cinar R, Gamble-George J, Sugden K, Williams B et al (2013). Convergent translational evidence of a role for anandamide in amygdala-mediated fear extinction, threat processing and stress-reactivity. Mol Psychiatry 18: 813-823.

Hill MN, Froese LM, Morrish AC, Sun JC, Floresco SB (2006). Alterations in behavioral flexibility by cannabinoid CB1 receptor agonists and antagonists. Psychopharmacology 187: 245-259.

Hill MN, Kumar SA, Filipski SB, Iverson M, Stuhr KL, Keith JM et al (2013). Disruption of fatty acid amide hydrolase activity prevents the effects of chronic stress on anxiety and amygdalar microstructure. Mol Psychiatry 18: 1125-1135.

Hill MN, McLaughlin RJ, Morrish AC, Viau V, Floresco SB, Hillard CJ et al (2009). Suppression of amygdalar endocannabinoid signaling by stress contributes to activation of the hypothalamicpituitary-adrenal axis. Neuropsychopharmacology 34: 2733-2745.

Hill MN, McLaughlin RJ, Pan B, Fitzgerald ML, Roberts CJ, Lee TT et al (2011). Recruitment of prefrontal cortical endocannabinoid signaling by glucocorticoids contributes to termination of the stress response. J Neurosci 31: 10506-10515.

Hill MN, Patel S, Campolongo P, Tasker JG, Wotjak CT, Bains JS (2010). Functional interactions between stress and the endocannabinoid system: from synaptic signaling to behavioral output. J Neurosci 30: 14980-14986.

Hohmann AG, Suplita RL, Bolton NM, Neely MH, Fegley D, Mangieri $\mathrm{R}$ et al (2005). An endocannabinoid mechanism for stress-induced analgesia. Nature 435: 1108-1112.

Holman EA, Guijarro A, Lim J, Piomelli D (2014). Effects of acute stress on cardiac endocannabinoids, lipogenesis, and inflammation in rats. Psychosom Med 76: 20-28.

Kano M, Ohno-Shosaku T, Hashimotodani Y, Uchigashima M, Watanabe M (2009). Endocannabinoid-mediated control of synaptic transmission. Physiol Rev 89: 309-380.

Kathuria S, Gaetani S, Fegley D, Valino F, Duranti A, Tontini A et al (2003). Modulation of anxiety through blockade of anandamide hydrolysis. Nat Med 9: 76-81.

Kessler RC, Berglund P, Demler O, Jin R, Merikangas KR, Walters EE (2005). Lifetime prevalence and age-of-onset distributions of DSM-IV disorders in the national comorbidity survey replication. Arch Gen Psychiat 62: 768-768.

LeDoux JE (2000). Emotion circuits in the brain. Ann Rev Neurosci 23: $155-184$.

Li H, Penzo MA, Taniguchi H, Kopec CD, Huang ZJ, Li B (2013). Experience-dependent modification of a central amygdala fear circuit. Nat Neurosci 16: 332-339.

Lutz B (2009). Endocannabinoid signals in the control of emotion. Curr Opin Pharmacol 9: 46-52.

Marsicano G, Lutz B (2006). Neuromodulatory functions of the endocannabinoid system. J Endocrinol Invest 29(3 Suppl): 27-46.
Marsicano G, Wotjak CT, Azad SC, Bisogno T, Rammes G, Cascio MG et al (2002). The endogenous cannabinoid system controls extinction of aversive memories. Nature 418: 530-534.

Neumeister A, Normandin MD, Pietrzak RH, Piomelli D, Zheng MQ, Gujarro-Anton A et al (2013). Elevated brain cannabinoid $\mathrm{CB}$ receptor availability in post-traumatic stress disorder: a positron emission tomography study. Mol Psychiatry 18: 1034-1040.

Pan B, Wang W, Long JZ, Sun D, Hillard CJ, Cravatt BF et al (2009). Blockade of 2-arachidonoylglycerol hydrolysis by selective monoacylglycerol lipase inhibitor 4-nitrophenyl 4-(dibenzo[d][1,3]dioxol5-yl(hydroxy)methyl)piperidine-1-carboxylate (JZL184) Enhances retrograde endocannabinoid signaling. J Pharmacol Exp Ther 331: 591-597.

Patel S, Hillard CJ (2006). Pharmacological evaluation of cannabinoid receptor ligands in a mouse model of anxiety: further evidence for an anxiolytic role for endogenous cannabinoid signaling. J Pharmacol Exp Ther 318: 304-311.

Patel S, Hillard CJ (2008). Adaptations in endocannabinoid signaling in response to repeated homotypic stress: a novel mechanism for stress habituation. Eur J Neurosci 27: 2821-2829.

Paxinos G, Watson C (1998). The Rat Brain in Stereotaxic Coordinates 4th edn. Academic Press: San Diego, CA, USA.

Pecoraro N, Dallman MF, Warne JP, Ginsberg AB, Laugero KD, la Fleur SE et al (2006). From Malthus to motive: how the HPA axis engineers the phenotype, yoking needs to wants. Prog Neurobiol 79: 247-340.

Piomelli D (2003). The molecular logic of endocannabinoid signalling. Nat Rev Neurosci 4: 873-884.

Piomelli D (2014). More surprises lying ahead. The endocannabinoids keep us guessing. Neuropharmacology 76: 228-234.

Pitman RK, Delahanty DL (2005). Conceptually driven pharmacologic approaches to acute trauma. CNS Spectr 10: 99-106.

Ramikie TS, Nyilas R, Bluett RJ, Gamble-George JC, Hartley ND, Mackie K et al (2014). Multiple mechanistically distinct modes of endocannabinoid mobilization at central amygdala glutamatergic synapses. Neuron 81: 1111-1125.

Ramikie TS, Patel S (2012). Endocannabinoid signaling in the amygdala: anatomy, synaptic signaling, behavior, and adaptations to stress. Neuroscience 204: 38-52.

Sciolino NR, Zhou W, Hohmann AG (2011). Enhancement of endocannabinoid signaling with JZL184, an inhibitor of the 2-arachidonoylglycerol hydrolyzing enzyme monoacylglycerol lipase, produces anxiolytic effects under conditions of high environmental aversiveness in rats. Pharmacol Res 64: 226-234.

Speckens AE, Ehlers A, Hackmann A, Clark DM (2006). Changes in intrusive memories associated with imaginal reliving in posttraumatic stress disorder. J Anxiety Disord 20: 328-341.

Steiner MA, Marsicano G, Nestler EJ, Holsboer F, Lutz B, Wotjak CT (2008). Antidepressant-like behavioral effects of impaired cannabinoid receptor type 1 signaling coincide with exaggerated corticosterone secretion in mice. Psychoneuroendocrinology 33: 54-67.

Sutt S, Raud S, Areda T, Reimets A, Koks S, Vasar E (2008). Cat odour-induced anxiety-a study of the involvement of the endocannabinoid system. Psychopharmacology 198: 509-520.

Zatzick D, Roy-Byrne P (2003). Developing high-quality interventions for posttraumatic stress disorder in the acute care medical setting. Semin Clin Neuropsychiatry 8: 158-167.

Zatzick D, Roy-Byrne PP (2006). From bedside to bench: how the epidemiology of clinical practice can inform the secondary prevention of PTSD. Psychiatr Serv 57: 1726-1730.

Zhang W, Davidson JR (2007). Post-traumatic stress disorder: an evaluation of existing pharmacotherapies and new strategies. Expert Opin Pharmacother 8: 1861-1870.

Supplementary Information accompanies the paper on the Neuropsychopharmacology website (http://www.nature.com/npp) 